\title{
Impacts of the urinary sodium-to-potassium ratio, sleep efficiency, and conventional risk factors on home hypertension in a general Japanese population
}

\author{
Takumi Hirata $^{1,2} \cdot$ Mana Kogure ${ }^{1,3} \cdot$ Naho Tsuchiya $^{1,3} \cdot K^{\prime}$ Miyagawa ${ }^{4} \cdot$ Akira Narita $^{1,3} \cdot$ Kotaro Nochioka $^{1,3,5} \cdot$ \\ Akira Uruno $^{1,3} \cdot$ Taku Obara $^{1,3,5} \cdot$ Tomohiro Nakamura $^{1,3} \cdot$ Naoki Nakaya $^{1,3,6} \cdot$ Hirohito Metoki ${ }^{1,7}$. \\ Masahiro Kikuya $^{1,8} \cdot$ Junichi Sugawara $^{1,3,5} \cdot$ Shinichi Kuriyama $^{1,3,9} \cdot$ Ichiro Tsuji $^{1,3} \cdot$ Shigeo Kure $^{1,3,5}$. \\ Atsushi Hozawa ${ }^{1,3}$
}

Received: 15 September 2020 / Revised: 14 December 2020 / Accepted: 19 December 2020 / Published online: 15 February 2021

(c) The Author(s) 2021. This article is published with open access

\begin{abstract}
Recently, a high urinary sodium-to-potassium $(\mathrm{Na} / \mathrm{K})$ ratio and reduced sleep efficiency, in addition to conventional risk factors (obesity and excess alcohol intake), have been identified as risk factors for hypertension. We estimated the population attributable fraction (PAF) for home hypertension due to these risk factors in a general Japanese population. We conducted a cross-sectional study including 1384 participants (393 men and 991 women) to estimate the odds ratio (OR) and 95\% confidence interval $(\mathrm{CI})$ for the presence of any of the conventional risk factors using multivariable logistic regression analyses. The models were adjusted for sex, age, smoking status, and log-transformed average daily steps. We also estimated the OR and $95 \%$ CI for the presence of any of the overall risk factors. Furthermore, we calculated the PAF due to these risk factors. The results showed that the prevalence of home hypertension was $39.0 \%(540 / 1384)$. The presence of any of the conventional risk factors, as well as any of the overall risk factors, was significantly associated with an increased prevalence of hypertension (OR 2.80, 95\% CI 2.15-3.65; OR 2.50, 95\% CI 1.93-3.22, respectively). The PAF for hypertension due to the presence of any of the conventional risk factors and the PAF due to the presence of any of the overall risk factors were $30.2 \%$ and $39.0 \%$, respectively. In conclusion, the impact of the overall risk factors, including the urinary $\mathrm{Na} / \mathrm{K}$ ratio and sleep efficiency, on home hypertension was higher than that of conventional risk factors alone. The management of the urinary $\mathrm{Na} / \mathrm{K}$ ratio and sleep efficiency as well as conventional risk factors might be important in the management of blood pressure.
\end{abstract}

Keywords Population attributable fraction $\cdot$ Home hypertension $\cdot$ Risk factor $\cdot$ Public health $\cdot$ Japanese

Supplementary information The online version contains supplementary material available at https://doi.org/10.1038/s41440021-00628-y.

Takumi Hirata

t-hirata@med.hokudai.ac.jp

1 Tohoku Medical Megabank Organization, Tohoku University, Sendai, Japan

2 Hokkaido University Faculty of Medicine, Sapporo, Japan

3 Graduate School of Medicine, Tohoku University, Sendai, Japan

4 OMRON Healthcare Co., Ltd., Muko, Japan

\section{Introduction}

Hypertension is the leading cause of cardiovascular diseases; thus, the prevention of hypertension is essential to reduce the burden of cardiovascular diseases [1-3]. Obesity and moderate-to-high alcohol consumption are conventional

5 Tohoku University Hospital, Tohoku University, Sendai, Japan

6 School of Health and Social Services, Saitama Prefectural University, Koshigaya, Japan

7 School of Medicine, Tohoku Medical and Pharmaceutical University, Sendai, Japan

8 Teikyo University School of Medicine, Tokyo, Japan

9 International Research Institute of Disaster Science, Tohoku University, Sendai, Japan 
risk factors for hypertension [4-8]. Accordingly, reductions in body weight and alcohol consumption are important measures to control blood pressure [9-14].

The urinary sodium-to-potassium $(\mathrm{Na} / \mathrm{K})$ ratio is also a predictive marker for hypertension [15-17]. In the INTERSALT study, the 24-h urinary $\mathrm{Na} / \mathrm{K}$ ratio had a stronger relationship with blood pressure than the 24-h urinary sodium (Na) level alone [15]. Additionally, a previous study demonstrated that the urinary $\mathrm{Na} / \mathrm{K}$ ratio in casual spot urine was highly correlated with the urinary $\mathrm{Na} /$ $\mathrm{K}$ ratio in 24-h urine samples (the gold standard examination) [18]. This means that the evaluation of the urinary $\mathrm{Na} /$ $\mathrm{K}$ ratio in casual spot urine can be conveniently performed in clinical settings or at health checkups. Similarly, sleep efficiency has been considered to be a predictor of hypertension. In fact, we have shown that reduced sleep efficiency is associated with the prevalence of hypertension [19]. These markers are expected to be lifestyle indicators related to the development of hypertension.

For the primary prevention of hypertension, the estimated population attributable fraction (PAF) provides meaningful information for public health. However, few studies have reported PAFs for hypertension in Japan due to the presence of several risk factors [20-25]. In particular, no previous studies have reported the PAFs for hypertension due to the urinary $\mathrm{Na} / \mathrm{K}$ ratio and sleep efficiency. In addition, whether the urinary $\mathrm{Na} / \mathrm{K}$ ratio and sleep efficiency as well as conventional risk factors contributes to the increase in PAFs for hypertension is unknown. Therefore, we estimated the PAFs for home hypertension due to the urinary $\mathrm{Na} / \mathrm{K}$ ratio, sleep efficiency and conventional risk factors in a Japanese general population.

\section{Methods}

\section{Participants}

This cross-sectional study was conducted to calculate the PAFs for home hypertension due to combinations of risk factors. Participants fulfilling the following criteria were included: (1) completed the follow-up survey in the Tohoku Medical Megabank project Cohort Study (TMM Cohort Study), which is population based and has been ongoing since 2013; (2) were aged $\geq 20$ years and lived in Miyagi Prefecture during the baseline survey from May 2013 to March 2016; (3) visited one community support center (located in Tagajo City in Miyagi Prefecture); and (4) measured home blood pressure, sleep efficiency, and the urinary $\mathrm{Na} / \mathrm{K}$ ratio and had counted their steps daily for at least 7 days. The participants in this present study were recruited from June 2017 to March 2018. Written informed consent was obtained from each participant. The study was approved by the Institutional Review Board of the TMM Organization (approval number: 2017-4-007).

A total of 1474 participants were initially included. However, 90 participants were excluded for missing data on (1) treatment status for hypertension $(n=33)$; (2) height, body weight, and alcohol consumption status $(n=53)$; and (3) sex, age, and smoking status $(n=4)$. Finally, we analyzed the data of 1384 participants (393 men and 991 women).

\section{Measurements}

1. Measurements of home hypertension

Home hypertension, the outcome of the present study, was defined as having a morning home blood pressure $\geq 135 / 85 \mathrm{mmHg}$ or receiving treatment for hypertension [26]. Information on treatment for hypertension was collected using a self-reported questionnaire. Home blood pressure was measured using a cuff-oscillometric device (HEM-7080IC; Omron Healthcare Co., Ltd., Kyoto, Japan) and was recorded for 10 days. Measurement was performed with the participant in a sitting position after at least $5 \mathrm{~min}$ of rest in the morning, within $1 \mathrm{~h}$ after awakening. The arm cuff was maintained at heart level during the measurement, and if applicable, the measurements were taken before the participants took their medications for hypertension and ate breakfast and after urination. We defined morning home blood pressure as the average of the first measurements performed each morning.

2. Measurements of conventional risk factors

We defined obesity and moderate-to-heavy daily alcohol intake as conventional risk factors in the present study. Obesity was defined as body mass index (BMI) $\geq 25 \mathrm{~kg} / \mathrm{m}^{2}$ based on the Western Pacific Region of the World Health Organization (WHO) criteria for the Japanese population [27]. Height and weight were measured in participants while they were wearing light clothing. BMI was calculated as weight $(\mathrm{kg})$ divided by the square of height $(\mathrm{m})$. Alcohol consumption status was assessed using a self-reported questionnaire, and we divided the participants into three groups (nondrinkers, past drinkers, and current drinkers). In addition, we asked all the current drinkers about the typical quantities of alcohol consumed per occasion and the typical consumption frequency per week for each type of alcohol. We calculated the mean daily alcohol intake as ethanol intake per day, and then, we defined moderate-toheavy daily alcohol intake as $\geq 46 \mathrm{~g}$ of ethanol intake per day. 


\section{Measurements of other risk factors}

We defined a high urinary $\mathrm{Na} / \mathrm{K}$ ratio and reduced sleep efficiency as new risk factors in the present study. The urinary $\mathrm{Na} / \mathrm{K}$ ratio was measured twice daily (in the morning after awakening and at night before going to bed) using a hand-held urinary $\mathrm{Na} / \mathrm{K}$ ratio monitor (HEU-001F; Omron Healthcare Co., Ltd., Kyoto, Japan) for 10 continuous days. We used the average of the values for all the measurements in the analysis. All the participants were grouped into four quartiles, and the highest quartile had a ratio $\geq 5.20$. Sleep efficiency was measured using a contactless biomotion sleep sensor (HSL-102M; Omron Healthcare Co., Ltd., Kyoto, Japan) for 10 days. The details of the measurement conducted using the sleep sensor are described elsewhere [28-30]. Sleep efficiency was defined as the ratio of the sleep duration ( $\mathrm{min})$ to the time spent in bed (min) multiplied by 100 [31]. We used the average of all measurements in the analysis. We defined reduced sleep efficiency as a sleep efficiency of $<85 \%$ in the present study $[32,33]$.

4. Measurements for the covariates

All the participants completed a self-reported questionnaire to obtain information on sex, age, and smoking status. The daily steps, one of the covariates in the present study, were counted using an activity monitor (HJA-750C; Omron Healthcare Co., Ltd., Kyoto, Japan). The activity monitor was positioned on the waist of each participant and was attached throughout the day, except while the participant was bathing or sleeping, for 11 continuous days. The data collected on the first of the 11 days were excluded. In addition, we excluded the data if the daily total measurement duration was less than $8 \mathrm{~h}$. We used the average of all measurements for this analysis.

\section{Statistical analysis}

Data are presented as the means (standard deviations) or medians (interquartile ranges) for continuous variables or numbers (percentages) for categorical variables. We used the unpaired $t$-test or Wilcoxon rank-sum test for continuous variables and the chi-square test or Fisher's exact test for categorical variables to compare the characteristics between the presence and absence of conventional or other risk factors. We divided all participants into four groups according to the presence or absence of conventional and other risk factors. Multivariable logistic regression models were used to obtain odds ratios (ORs) and 95\% confidence intervals (CIs) to assess the relationship of each conventional and other risk factor with the prevalence of home hypertension. Models were adjusted for sex, age, smoking status, and log-transformed average daily steps. In addition, we calculated the PAF for each group using the following formula: (the proportion of participants with home hypertension)*(Adjusted OR-1)/(Adjusted OR) [7, 34]. Next, we used the multivariable logistic regression model to assess the relationship between the presence of conventional risk factors and the prevalence of hypertension. We also used the multivariable logistic regression model to assess the relationship between the presence of conventional risk factors and prevalent hypertension and the relationship between the presence of conventional and/or other risk factors and prevalent hypertension. Additionally, we performed the same analyses described above stratified by age ( $<65$ years and $\geq 65$ years). Two-sided $P$ values of $<0.05$ were considered statistically significant. All analyses were performed using STATA SE 13 data analysis and statistical software (Stata Corp LP, College Station, TX, USA).

\section{Results}

The clinical characteristics of the participants at the baseline survey according to the type of risk factors are shown in Table 1. Of 1384 participants, 198 (14.3\%) had conventional and other risk factors (i.e., highest quartile of urinary $\mathrm{Na} / \mathrm{K}$ ratio and reduced sleep efficiency), 257 (18.6\%) had conventional risk factors only, $280(20.2 \%)$ had other risk factors only, and 649 (46.9\%) had neither conventional nor other risk factors. The proportions of participants according to the presence or absence of conventional and/or other risk factors are summarized in Supplemental Table 1. Of 1384 participants, $540(39.0 \%)$ had home hypertension, and the prevalence was highest $(64.7 \%)$ in participants with conventional and other risk factors. The group with conventional and other risk factors had more men $(52.0 \%)$ and current smokers $(10.1 \%)$ and the lowest daily average steps $\left(5.5 \times 10^{3}\right.$ steps per day) compared to the remaining three groups.

The associations between the presence of each of risk factors, including conventional and/or other risk factors, and home hypertension are shown in Table 2. In multivariate analyses, the presence of each of risk factors was significantly associated with an increased prevalence of hypertension when adjusted for potential confounders (obesity, OR 3.14, 95\% CI 2.33-4.25; moderate-to-high alcohol consumption, OR 1.52, 95\% CI 1.06-2.19; highest quartile of urinary $\mathrm{Na} / \mathrm{K}$ ratio, OR $1.40 ; 95 \%$ CI 1.04-1.88; reduced sleep efficiency, OR $2.51,95 \%$ CI 1.71-3.70). The estimated PAFs for hypertension due to obesity, moderateto-high alcohol consumption, the highest quartile of the urinary $\mathrm{Na} / \mathrm{K}$ ratio, and reduced sleep efficiency were $23.7 \%, 6.5 \%, 7.9 \%$, and $11.6 \%$, respectively.

The association between conventional risk factors and home hypertension and the association between overall risk 
Table 1 Clinical characteristics of participants according to the combinations of conventional and other risk factors

\begin{tabular}{|c|c|c|c|c|c|}
\hline & Total participants & $\begin{array}{l}\text { Conventional }(+) \\
\text { Other }(+)\end{array}$ & $\begin{array}{l}\text { Conventional }(+) \\
\text { Other }(-)\end{array}$ & $\begin{array}{l}\text { Conventional (-) } \\
\text { Other }(+)\end{array}$ & $\begin{array}{l}\text { Conventional (-) } \\
\text { Other (-) }\end{array}$ \\
\hline Number of participants & 1384 & 198 & 257 & 280 & 649 \\
\hline Sex, men & $393(28.4 \%)$ & $103(52.0 \%)$ & $96(37.4 \%)$ & $75(26.8 \%)$ & $119(18.3 \%)$ \\
\hline Age, years & $58.8(12.9)$ & $58.3(13.7)$ & $60.0(12.0)$ & $55.7(14.0)$ & $59.9(12.3)$ \\
\hline$\geq 65$ years & $589(42.6 \%)$ & $83(41.9 \%)$ & $117(45.5 \%)$ & $99(35.4 \%)$ & $290(44.7 \%)$ \\
\hline Current smoker, yes & $89(6.4 \%)$ & $20(10.1 \%)$ & $20(7.8 \%)$ & $25(8.9 \%)$ & $24(3.7 \%)$ \\
\hline Average daily steps, 1000 steps per day & $6.0(4.6-7.8)$ & $5.5(4.2-7.5)$ & $6.1(4.5-7.8)$ & $6.1(4.7-8.1)$ & $6.2(4.7-7.9)$ \\
\hline Conventional risk factors for hypertension, yes & $455(32.9 \%)$ & $198(100.0 \%)$ & $257(100.0 \%)$ & $0(0.0 \%)$ & $0(0.0 \%)$ \\
\hline Body mass index, $\mathrm{kg} / \mathrm{m}^{2}$ & $22.9(3.3)$ & $26.1(3.7)$ & $25.6(3.4)$ & $21.5(2.0)$ & $21.4(2.0)$ \\
\hline$\geq 25$, yes & $312(22.5 \%)$ & $136(68.7 \%)$ & $176(68.5 \%)$ & $0(0.0 \%)$ & $0(0.0 \%)$ \\
\hline Current alcohol drinker, yes & $673(48.6 \%)$ & $141(71.2 \%)$ & $170(66.2 \%)$ & $124(44.3 \%)$ & $238(36.7 \%)$ \\
\hline$\geq 46 \mathrm{~g} /$ day, yes & $196(14.2 \%)$ & $86(43.4 \%)$ & $110(42.8 \%)$ & $0(0.0 \%)$ & $0(0.0 \%)$ \\
\hline Other risk factors for hypertension, yes & $478(34.5 \%)$ & $198(100.0 \%)$ & $0(0.0 \%)$ & $280(100.0 \%)$ & $0(0.0 \%)$ \\
\hline Urinary $\mathrm{Na} / \mathrm{K}$ ratio & $4.4(1.6)$ & $5.7(1.7)$ & $3.8(0.9)$ & $5.9(1.8)$ & $3.5(0.9)$ \\
\hline$\geq 5.2$ (Highest quartile), yes & $345(24.9 \%)$ & $136(68.7 \%)$ & $0(0.0 \%)$ & $209(74.6 \%)$ & $0(0.0 \%)$ \\
\hline Sleep efficiency, $\%$ & $91.1(6.2)$ & $86.1(8.2)$ & $92.4(3.7)$ & $88.2(7.8)$ & $93.4(3.5)$ \\
\hline$<85 \%$, yes & $190(13.7 \%)$ & $89(45.0 \%)$ & $0(0.0 \%)$ & $101(36.1 \%)$ & $0(0.0 \%)$ \\
\hline Hypertension, yes & $540(39.0 \%)$ & $128(64.7 \%)$ & $126(49.0 \%)$ & $97(34.6 \%)$ & $189(29.1 \%)$ \\
\hline Systolic blood pressure, $\mathrm{mmHg}$ & $125.0(16.1)$ & $133.1(15.3)$ & $129.0(15.2)$ & $124.4(16.9)$ & $121.2(15.1)$ \\
\hline Diastolic blood pressure, $\mathrm{mmHg}$ & $75.0(9.8)$ & $80.4(9.7)$ & $77.4(9.0)$ & $74.7(9.5)$ & $72.6(9.3)$ \\
\hline Received treatment for hypertension, yes & $281(20.3 \%)$ & $70(35.4 \%)$ & $66(25.7 \%)$ & $43(15.4 \%)$ & $102(15.7 \%)$ \\
\hline
\end{tabular}

$\mathrm{Na} / \mathrm{K}$ sodium-to-potassium.

Table 2 Association between each risk factor and home hypertension

\begin{tabular}{|c|c|c|c|c|c|c|}
\hline & $\begin{array}{l}\text { Number of the total } \\
\text { participants }\end{array}$ & $\begin{array}{l}\text { Number of participants } \\
\text { with home hypertension }\end{array}$ & OR & $95 \% \mathrm{CI}$ & $P$ value & PAF \\
\hline \multicolumn{7}{|c|}{ Conventional risk factors for hypertension } \\
\hline \multicolumn{7}{|c|}{ Body mass index, $\mathrm{kg} / \mathrm{m}^{2}$} \\
\hline$\geq 25$, yes & 312 & 188 & 3.14 & $2.33-4.25$ & $<0.001$ & $23.7 \%$ \\
\hline \multicolumn{7}{|l|}{ Current alcohol drinker } \\
\hline$\geq 46 \mathrm{~g} /$ day & 196 & 102 & 1.52 & $1.06-2.19$ & 0.024 & $6.5 \%$ \\
\hline \multicolumn{7}{|c|}{ Other risk factors for hypertension } \\
\hline \multicolumn{7}{|l|}{ Urinary $\mathrm{Na} / \mathrm{K}$ ratio } \\
\hline$\geq 5.2$ (Highest quartile) & 345 & 150 & 1.40 & $1.04-1.88$ & 0.025 & $7.9 \%$ \\
\hline \multicolumn{7}{|l|}{ Sleep efficiency, $\%$} \\
\hline$<85 \%$ & 190 & 104 & 2.51 & $1.71-3.70$ & $<0.001$ & $11.6 \%$ \\
\hline Sex, men & & & 1.80 & $1.35-2.41$ & $<0.001$ & \\
\hline Age, per 10 years & & & 2.14 & $1.89-2.43$ & $<0.001$ & \\
\hline Current smoker, yes & & & 1.49 & $0.90-2.47$ & 0.125 & \\
\hline $\begin{array}{l}\text { Average daily steps, log- } \\
\text { transformed }\end{array}$ & & & 0.87 & $0.65-1.15$ & 0.319 & \\
\hline
\end{tabular}

$\mathrm{Na} / \mathrm{K}$ sodium-to-potassium, $\mathrm{OR}$ odds ratio, $\mathrm{CI}$ confidence interval, $\mathrm{PAF}$ population attributable fraction.

factors, including conventional and/or other risk factors, and home hypertension are shown in Table 3. In multivariate analyses, the presence of any of conventional risk factors was significantly associated with an increased prevalence of hypertension after adjusting for potential confounders (OR 2.80, 95\% CI 2.15-3.65; as shown in Table 3A). The estimated PAF for hypertension in participants with any of the conventional risk factors was $30.2 \%$. On the other hand, the 
Table 3 Association between conventional risk factors only or all risk factors and home hypertension

Number of the total Number of participants with home participants hypertension

(A) Measured only conventional risk factors for hypertension

\begin{tabular}{|c|c|c|c|c|c|c|}
\hline $\begin{array}{l}\text { Any of conventional risk } \\
\text { factors, yes }\end{array}$ & 455 & 254 & 2.80 & $2.15-3.65$ & $<0.001$ & $30.2 \%$ \\
\hline Sex, men & & & 1.99 & $1.50-2.63$ & $<0.001$ & \\
\hline Age, per 10 years & & & 2.00 & $1.78-2.26$ & $<0.001$ & \\
\hline Current smoker, yes & & & 1.56 & $0.95-2.57$ & 0.081 & \\
\hline $\begin{array}{l}\text { Average daily steps, log- } \\
\text { transformed }\end{array}$ & & & 0.81 & $0.61-1.07$ & 0.142 & \\
\hline Measured all risk factors inc & g cor & inar & yperte & ension & & \\
\hline Any of all risk factors, yes & 735 & 351 & 2.50 & $1.93-3.22$ & $<0.001$ & $39.0 \%$ \\
\hline Sex, men & & & 2.03 & $1.54-2.68$ & $<0.001$ & \\
\hline Age, per 10 years & & & 2.04 & $1.81-2.29$ & $<0.001$ & \\
\hline Current smoker, yes & & & 1.46 & $0.89-2.41$ & 0.137 & \\
\hline $\begin{array}{l}\text { Average daily steps, log- } \\
\text { transformed }\end{array}$ & & & 0.79 & $0.60-1.05$ & 0.102 & \\
\hline
\end{tabular}

$O R$ odds ratio, $C I$ confidence interval, $P A F$ population attributable fraction, $\mathrm{Na} / \mathrm{K}$ sodium-to-potassium.

presence of any of the overall risk factors was significantly associated with an increased prevalence of hypertension in multivariate analyses (OR 2.50, 95\% CI 1.93-3.22; as shown in Table 3B). The estimated PAF of hypertension in participants with any of the overall risk factors was $39.0 \%$.

The association between conventional risk factors and home hypertension and the association between conventional and/or other risk factors and home hypertension stratified by age are shown in Table 4. In participants aged $<65$ and $\geq 65$ years, the presence of any of conventional risk factors was significantly associated with an increased prevalence of hypertension after adjusting for potential confounders ( $<65$ years, OR 3.38, 95\% CI 2.34-4.87; $\geq 65$ years, OR 2.28, 95\% CI 1.55-3.34). The estimated PAFs for hypertension in participants with any of the conventional risk factors aged $<65$ and $\geq 65$ years were $30.2 \%$ and $24.1 \%$, respectively. Similarly, in these age groups, the presence of any of conventional and/or other risk factors was significantly associated with an increased prevalence of hypertension in multivariate analyses $(<65$ years, OR 2.70 , 95\% CI 1.85-3.93; $\geq 65$ years, OR 2.35, 95\% CI 1.65-3.34). The estimated PAFs for hypertension among participants with any of conventional and/or other risk factors aged $<65$ and $\geq 65$ years were $44.9 \%$ and $35.2 \%$, respectively.

\section{Discussion}

The results of the present study showed that both conventional and other risk factors were significantly positively related to the prevalence of home hypertension. The PAF for hypertension due to any of the conventional risk factors was $30.2 \%$, and that due to any of the conventional and/or other risk factors increased to $39.0 \%$. In age-stratified analyses, both the PAF for hypertension due to any of conventional risk factors and that due to any of conventional and/or other risk factors in participants aged $<65$ years were higher than those in participants aged $\geq 65$ years.

All established risk factors, including obesity, moderateto-high alcohol consumption, the highest quartile of the urinary $\mathrm{Na} / \mathrm{K}$ ratio, and reduced sleep efficiency, were also significantly associated with home hypertension in the present study. We found the largest PAFs to be due to obesity, followed by reduced sleep efficiency, the highest quartile of the urinary $\mathrm{Na} / \mathrm{K}$ ratio, and moderate-to-high alcohol consumption. Previous studies have shown that the PAFs for hypertension due to obesity or BMI were the largest among several risk factors for hypertension [20, 21]. Our findings are consistent with those of these previous studies, which suggests that the reduction in body weight should be a priority for the prevention of hypertension in the context of global public health. In fact, a meta-analysis of randomized controlled trials (RCTs) revealed that weight reduction of $5.1 \mathrm{~kg}$ decreased systolic blood pressure by $4.78 \mathrm{mmHg}$ and diastolic blood pressure by $3.56 \mathrm{mmHg}$ [9]. Additionally, reduced alcohol consumption and sodium intake and increased potassium intake had favorable effects on the prevention of hypertension in meta-analyses of RCTs [35-37]. These findings suggest that these are modifiable risk factors that are worth managing to prevent hypertension.

In the present study, the PAF for hypertension due to the presence of any of conventional risk factors was $30.2 \%$, and the PAF due to the presence of any of conventional and/or other risk factors increased to $39.0 \%$. The magnitude of the 
Table 4 Association between conventional risk factors only or all risk factors and home hypertension stratified by age

Number of the total participants Number of participants with home OR 95\% CI $P$ value PAF hypertension

(A) Measured only conventional risk factors for hypertension

(A-1) $<65$ years old 795

202

Any of conventional risk factors, yes 255

109

$\begin{array}{llll}3.38 & 2.34-4.87<0.001 \quad 38.0 \%\end{array}$

Sex, men

$2.13 \quad 1.74-2.60<0.001$

Age, per 10 years

Current smoker, yes

$\begin{array}{lll}1.40 & 0.77-2.55 & 0.273\end{array}$

Average daily steps, log-transformed

$\begin{array}{lll}0.86 & 0.55-1.33 & 0.494\end{array}$

(A-2) $\geq 65$ years old 589

Any of conventional risk factors, yes 200

338

Sex, men

$2.28 \quad 1.55-3.34<0.001 \quad 24.1 \%$

Age, per 10 years

Current smoker, yes

Average daily steps, log-transformed

$\begin{array}{lll}1.70 & 1.18-2.47 \quad 0.005\end{array}$

$\begin{array}{lll}1.30 & 0.83-2.03 & 0.255\end{array}$

$\begin{array}{llll}1.68 & 0.62-4.56 & 0.308\end{array}$

$0.73 \quad 0.51-1.06 \quad 0.096$

(B) Measured all risk factors including conventional risk factors, urinary $\mathrm{Na} / \mathrm{K}$ ratio and sleep efficiency for hypertension

\begin{tabular}{|c|c|c|c|c|c|c|}
\hline$(B-1)<65$ years old & 795 & \multicolumn{5}{|l|}{202} \\
\hline Any of all risk factors, yes & 436 & 144 & 2.70 & $1.85-3.93$ & $<0.001$ & $44.9 \%$ \\
\hline Sex, men & & & 2.89 & $1.87-4.46$ & $<0.001$ & \\
\hline Age, per 10 years & & & 2.18 & $1.79-2.66$ & $<0.001$ & \\
\hline Current smoker, yes & & & 1.35 & $0.74-2.44$ & 0.325 & \\
\hline Average daily steps, log-tra & & & 0.81 & $0.52-1.24$ & 0.334 & \\
\hline$(B-2) \geq 65$ years old & 589 & 338 & & & & \\
\hline Any of all risk factors, yes & 299 & 207 & 2.35 & $1.65-3.34$ & $<0.001$ & $35.2 \%$ \\
\hline Sex, men & & & 1.67 & $1.15-2.42$ & 0.007 & \\
\hline Age, per 10 years & & & 1.32 & $0.84-2.07$ & 0.228 & \\
\hline Current smoker, yes & & & 1.49 & $0.55-4.03$ & 0.435 & \\
\hline Average daily steps, log-tra & & & 0.73 & $0.51-1.06$ & 0.098 & \\
\hline
\end{tabular}

OR odds ratio, $C I$ confidence interval, $P A F$ population attributable fraction, $\mathrm{Na} / \mathrm{K}$ sodium-to-potassium.

OR of the presence of any of conventional risk factors only is higher than that of the presence of any of the overall risk factors, and the increased PAF due to the presence of any of the overall risk factors merely reflects the increased prevalence of participants with risk factors. However, in participants without conventional risk factors, the presence of the highest quartile of urinary $\mathrm{Na} / \mathrm{K}$ ratio or reduced sleep efficiency was significantly associated with the prevalence of hypertension (OR, 1.68; 95\% CI, 1.19-2.37). Therefore, the urinary $\mathrm{Na} / \mathrm{K}$ ratio and sleep efficiency contributed to the maintenance of blood pressure even in individuals without conventional risk factors. As mentioned earlier, the favorable effect of decreased sodium intake and increased potassium intake on blood pressure was clarified in previous intervention studies [36, 37]. On the other hand, although some interventional approaches, such as sleep hygiene education and cognitive behavioral insomnia therapy, improve sleep efficiency [38, 39], the effect on blood pressure reduction has not been sufficiently clarified $[40,41]$. Further studies are warranted to explore the effect of interventional approaches to improve sleep efficiency on the prevention of hypertension.

Regardless of the age group, the PAF for hypertension due to conventional and/or other risk factors was higher than that due to conventional risk factors in the present study. Moreover, both PAF due to conventional risk factors and PAF due to conventional and/or other risk factors among participants aged $<65$ years were higher than those among participants aged $\geq 65$ years. The frequency of risk was almost the same between the two age groups in the present study; however, the magnitude of the risk among participants aged $<65$ years was higher than that among participants aged $\geq 65$ years. Previous studies have also shown that the risk of developing hypertension among younger individuals was higher than that among older individuals [23]. These risk factors increase the activity of the sympathetic nervous system, which leads to increased blood pressure [42, 43], and the activity of the sympathetic nervous system decreases with age [44]. Accordingly, our findings suggest that the management of all risk factors, 
including conventional risk factors, the urinary $\mathrm{Na} / \mathrm{K}$ ratio and sleep efficiency, is important, particularly in younger patients, to reduce the burden of hypertension.

The strengths of the present study included the measurement of the urinary $\mathrm{Na} / \mathrm{K}$ ratio and sleep efficiency using simple and objective devices, adopting a selfmonitoring and self-control approach that could be widely used in the general population. In addition, the present study focused on home hypertension, not office hypertension. Previous studies have reported that home blood pressure is superior to office blood pressure for predicting left ventricular hypertrophy and the risk of future cardiovascular events $[45,46]$. However, we need to consider the limitations when interpreting the results of this study. First, this was a cross-sectional study; thus, the causal relationships between risk factors and hypertension could not be established. Further studies are warranted to estimate PAFs due to the risk factors in longitudinal studies. Second, the PAF is usually calculated based on the risk ratio in cohort studies. We used the PAF in this cross-sectional study because the concept of PAF is important to indicate the importance of reducing risk factors in the field of public health, and the PAF was used for this purpose in the previous crosssectional study [7]. The value of PAF in the present study should be interpreted with caution because the prevalence of hypertension was not low. Third, we set the highest quartile (i.e., 5.20) as the cutoff value for the risk of hypertension in the present study, but the association between the urinary $\mathrm{Na} / \mathrm{K}$ ratio and the prevalence of hypertension was linear, and it is difficult to determine the cutoff value of the urinary $\mathrm{Na} / \mathrm{K}$ ratio for the risk of hypertension. The validity of the cutoff value needs to be verified in the future.

In conclusion, the urinary $\mathrm{Na} / \mathrm{K}$ ratio and/or sleep efficiency increased the burden of hypertension in the present study. This finding was shown regardless of the age group. The management of the urinary $\mathrm{Na} / \mathrm{K}$ ratio and sleep efficiency as well as conventional risk factors is desired to prevent hypertension.

Acknowledgements The authors would like to thank the members of the Tohoku Medical Megabank Organization, including genome medical research coordinators (GMRCs), and office and administrative personnel for their assistance (https://www.megabank.tohoku.ac.jp/ english/a201201/). We borrowed the home blood pressure monitors, sleep sensors, and urinary sodium/potassium monitors from Omron Healthcare Co., Ltd.

Funding This work was supported by grants from the Reconstruction Agency, the Ministry of Education, Culture, Sports, Science and Technology (MEXT), and the Japan Agency for Medical Research and Development (AMED) (JP15km0105001, JP16km0105001, JP17km0105001). The present study was also funded by Omron Healthcare Co., Ltd.

Author contributions AH contributed to the study design. MK, NT, AN, AU, TN, NN, HM, MK, JS, SK, and AH collected the data. TH performed the statistical analysis and prepared the first draft of the paper. All the authors contributed intellectually to the revision of the article and approved the final version.

\section{Compliance with ethical standards}

Conflict of interest TH, MK, NT, AN, AU, TN, NN, HM, MK, JS, $\mathrm{SK}$, and AH received research grants from Omron Healthcare Co., Ltd. $\mathrm{KM}$ is an employee of Omron Healthcare Co., Ltd. The other authors declare no competing interest.

Publisher's note Springer Nature remains neutral with regard to jurisdictional claims in published maps and institutional affiliations.

Open Access This article is licensed under a Creative Commons Attribution 4.0 International License, which permits use, sharing, adaptation, distribution and reproduction in any medium or format, as long as you give appropriate credit to the original author(s) and the source, provide a link to the Creative Commons license, and indicate if changes were made. The images or other third party material in this article are included in the article's Creative Commons license, unless indicated otherwise in a credit line to the material. If material is not included in the article's Creative Commons license and your intended use is not permitted by statutory regulation or exceeds the permitted use, you will need to obtain permission directly from the copyright holder. To view a copy of this license, visit http://creativecommons. org/licenses/by/4.0/.

\section{References}

1. Ikeda $\mathrm{N}$, Inoue $\mathrm{M}$, Iso $\mathrm{H}$, Ikeda $\mathrm{S}$, Satoh $\mathrm{T}$, Noda $\mathrm{M}$, et al. Adult mortality attributable to preventable risk factors for noncommunicable diseases and injuries in Japan: a comparative risk assessment. PLoS Med. 2012;9:e1001160.

2. Fujiyoshi A, Ohkubo T, Miura K, Murakami Y, Nagasawa SY, Okamura $\mathrm{T}$, et al. Blood pressure categories and long-term risk of cardiovascular disease according to age group in Japanese men and women. Hypertens Res. 2012;35:947-53.

3. Lewington S, Clarke R, Qizilbash N, Peto R, Collins R.Prospective Studies Collaboration. Age-specific relevance of usual blood pressure to vascular mortality: a meta-analysis of individual data for one million adults in 61 prospective studies. Lancet. 2002;360:1903-13.

4. Ishikawa-Takata K, Ohta T, Moritaki K, Gotou T, Inoue S. Obesity, weight change and risks for hypertension, diabetes and hypercholesterolemia in Japanese men. Eur J Clin Nutr. 2002;56:601-7.

5. Chei CL, Iso H, Yamagishi K, Tanigawa T, Cui R, Imano H, et al. Body fat distribution and the risk of hypertension and diabetes among Japanese men and women. Hypertens Res. 2008;31:851-7.

6. Tsujimoto T, Sairenchi T, Iso H, Irie F, Yamagishi K, Tanaka K, et al. Impact of obesity on incident hypertension independent of weight gain among nonhypertensive Japanese: the Ibaraki Prefectural Health Study (IPHS). J Hypertens. 2012;30:1122-8.

7. Nakamura K, Okamura T, Hayakawa T, Hozawa A, Kadowaki T, Murakami Y, et al. The proportion of individuals with alcoholinduced hypertension among total hypertensives in a general Japanese population: NIPPON DATA90. Hypertens Res. 2007; 30:663-8.

8. Marmot MG, Elliott P, Shipley MJ, Dyer AR, Ueshima H, Beevers DG, et al. Alcohol and blood pressure: the INTERSALT study. BMJ. 1994;308:1263-7.

9. Neter JE, Stam BE, Kok FJ, Grobbee DE, Geleijnse JM. Influence of weight reduction on blood pressure: a meta-analysis of randomized controlled trials. Hypertension. 2003;42:878-84.

10. Semlitsch T, Jeitler K, Berghold A, Horvath K, Posch N, Poggenburg $\mathrm{S}$, et al. Long-term effects of weight-reducing diets in 
people with hypertension. Cochrane Database Syst Rev. 2016;3: CD008274.

11. Muramoto A, Matsushita M, Kato A, Yamamoto N, Koike G, Nakamura M, et al. Three percent weight reduction is the minimum requirement to improve health hazards in obese and overweight people in Japan. Obes Res Clin Pr. 2014;8:e466-75.

12. Puddey IB, Beilin LJ, Vandongen R. Regular alcohol use raises blood pressure in treated hypertensive subjects. A randomized controlled trial. Lancet. 1987;1:647-51.

13. Ueshima H, Mikawa K, Baba S, Sasaki S, Ozawa H, Tsushima M, et al. Effect of reduced alcohol consumption on blood pressure in untreated hypertensive men. Hypertension. 1993;21:248-52.

14. Mattace-Raso FUS, van der Cammen TJM, Knetsch AM, van den Meiracker AH, Schalekamp MADH, Hofman A, et al. Arterial stiffness as the candidate underlying mechanism for postural blood pressure changes and orthostatic hypotension in older adults: the Rotterdam Study. J Hypertens. 2006;24:339-44.

15. Intersalt Cooperative Research Group. Intersalt: an international study of electrolyte excretion and blood pressure. Results for $24 \mathrm{~h}$ urinary sodium and potassium excretion. BMJ. 1988;297:319-28.

16. Kogure M, Hirata T, Nakaya N, Tsuchiya N, Nakamura T, Narita $\mathrm{A}$, et al. Multiple measurements of the urinary sodium-topotassium ratio strongly related home hypertension: TMM Cohort Study. Hypertens Res. 2020;43:62-71.

17. Thi Minh Nguyen $T$, Miura $K$, Tanaka-Mizuno S, Tanaka $T$, Nakamura Y, Fujiyoshi A, et al. Association of blood pressure with estimates of 24-h urinary sodium and potassium excretion from repeated single-spot urine samples. Hypertens Res. 2019;42: 411-8.

18. Iwahori $\mathrm{T}$, Miura $\mathrm{K}$, Ueshima $\mathrm{H}$, Chan $\mathrm{Q}$, Dyer AR, Elliott $\mathrm{P}$, et al. Estimating 24-h urinary sodium/potassium ratio from casual ('spot') urinary sodium/potassium ratio: the INTERSALT Study. Int J Epidemiol. 2017;46:1564-72.

19. Hirata T, Nakamura T, Kogure M, Tsuchiya N, Narita A, Miyagawa $\mathrm{K}$, et al. Reduced sleep efficiency, measured using an objective device, was related to an increased prevalence of home hypertension in Japanese adults. Hypertens Res. 2020;43:23-29.

20. Lee HA, Park H. Diet-related risk factors for incident hypertension during an 11-year follow-up: the Korean Genome Epidemiology Study. Nutrients. 2018;10:1077.

21. Bernabé-Ortiz A, Carrillo-Larco RM, Gilman RH, Checkley W, Smeeth L, Miranda JJ, et al. Impact of urbanization and altitude on the incidence of, and risk factors for, hypertension. Heart. 2017;103:827-33.

22. Smith PM, Mustard CA, Lu H, Glazier RH. Comparing the risk associated with psychosocial work conditions and health behaviours on incident hypertension over a nine-year period in Ontario, Canada. Can J Public Health. 2013;104:e82-6.

23. Cohen L, Curhan GC, Forman JP. Influence of age on the association between lifestyle factors and risk of hypertension. J Am Soc Hypertens. 2012;6:284-90.

24. Forman JP, Stampfer MJ, Curhan GC. Diet and lifestyle risk factors associated with incident hypertension in women. JAMA. 2009;302:401-11.

25. Okosun IS, Choi S, Dent MM, Jobin T, Dever GE. Abdominal obesity defined as a larger than expected waist girth is associated with racial/ethnic differences in risk of hypertension. J Hum Hypertens. 2001;15:307-12.

26. Asayama K, Satoh M, Kikuya M. Diurnal blood pressure changes. Hypertens Res. 2018;41:669-78.

27. WHO/IASO/IOTF. The Asia-Pacific perspective: redefining obesity and its treatment. Australia: Health Communications Australia Pty Ltd.; 2000.
28. De Chazal P, Fox N, O’Hare E, Heneghan C, Zaffaroni A, Boyle $\mathrm{P}$, et al. Sleep/wake measurement using a non-contact biomotion sensor. J Sleep Res. 2011;20:356-66.

29. Hashizaki M, Nakajima H, Tsutsumi M, Shiga T, Chiba S, Yagi $\mathrm{T}$, et al. Accuracy validation of sleep measurements by a contactless biomotion sensor on subjects with suspected sleep apnea. Sleep Biol Rhythms. 2014;12:106-15.

30. O'Hare E, Flanagan D, Penzel T, Garcia C, Frohberg D, Heneghan C. A comparison of radio-frequency biomotion sensors and actigraphy versus polysomnography for the assessment of sleep in normal subjects. Sleep Breath. 2015;19:91-98.

31. Hashizaki M, Nakajima H, Kume K. Monitoring of weekly sleep pattern variations at home with a contactless biomotion sensor. Sensors. 2015; 15:18950-64.

32. Schutte-Rodin S, Broch L, Buysse D, Dorsey C, Sateia M. Clinical guideline for the evaluation and management of chronic insomnia in adults. J Clin Sleep Med. 2008;4:487-504.

33. MartinezAguirre-Betolaza A, Maldonado-Martín S, Corres P, Gorostegi-Anduaga I, Aispuru GR, Mujika I. Actigraphy-based sleep analysis in sedentary and overweight/obese adults with primary hypertension: data from the EXERDIET-HTA study. Sleep Breath. 2019;23:1265-73.

34. Rockhill B, Newman B, Weinberg C. Use and misuse of population attributable fractions. Am J Public Health. 1998;88:15-19.

35. Xin X, He J, Frontini MG, Ogden LG, Motsamai OI, Whelton PK. Effects of alcohol reduction on blood pressure: a meta-analysis of randomized controlled trials. Hypertension. 2001;38:1112-7.

36. He FJ, MacGregor GA. Effect of modest salt reduction on blood pressure: a meta-analysis of randomized trials. Implications for public health. J Hum Hypertens. 2002;16:761-70.

37. Poorolajal J, Zeraati F, Soltanian AR, Sheikh V, Hooshmand E, Maleki A. Oral potassium supplementation for management of essential hypertension: a meta-analysis of randomized controlled trials. PLoS One. 2017;12:e0174967.

38. Kaku A, Nishinoue N, Takano T, Eto R, Kato N, Ono Y, et al. Randomized controlled trial on the effects of a combined sleep hygiene education and behavioral approach program on sleep quality in workers with insomnia. Ind Health. 2012;50:52-59.

39. Carney CE, Edinger JD, Kuchibhatla M, Lachowski AM, Bogouslavsky O, Krystal AD, et al. Cognitive behavioral insomnia therapy for those with insomnia and depression: a randomized controlled clinical trial. Sleep. 2017;40:zsx019.

40. Shechter A, Westwood AJ. A behavioral intervention for insomnia improves blood pressure. Sleep Med. 2017;37:225.

41. Ali W, Gao G, Bakris GL. Improved sleep quality improves blood pressure control among patients with chronic kidney disease: a pilot study. Am J Nephrol. 2020;51:249-54.

42. Jarrin DC, Alvaro PK, Bouchard MA, Jarrin SD, Drake CL, Morin CM. Insomnia and hypertension: a systematic review. Sleep Med Rev. 2018;41:3-38.

43. Bravo PE, Morse S, Borne DM, Aguilar EA, Reisin E. Leptin and hypertension in obesity. Vasc Health Risk Manag. 2006;2:163-9.

44. Hogikyan RV, Supiano MA. Arterial alpha-adrenergic responsiveness is decreased and SNS activity is increased in older humans. Am J Physiol. 1994;266:E717-24.

45. Sivén SSE, Niiranen TJ, Langén VLJ, Puukka PJ, Kantola IM, Jula AM. Home versus office blood pressure: longitudinal relations with left ventricular hypertrophy: the Finn-Home study. J Hypertens. 2017;35:266-71.

46. Niiranen TJ, Hänninen MR, Johansson J, Reunanen A, Jula AM. Home-measured blood pressure is a stronger predictor of cardiovascular risk than office blood pressure: the Finn-Home study. Hypertension. 2010;55:1346-51. 